Special Issue of the 6th International Congress \& Exhibition (APMAS2016), Maslak, Istanbul, Turkey, June 1-3, 2016

\title{
Effect of the Inclination of Mold Walls on Primary Cooling During the Continuous Casting of Steel
}

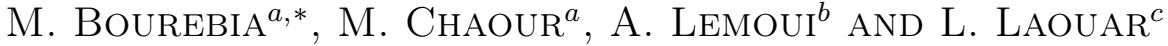 \\ ${ }^{a}$ Research Centre in Industrial Technology. Crti. Ex-Csc, Algeria \\ ${ }^{b}$ University Badji Mokhtar Bp 12-2300, Laboratory of Shaping of Metallic Materials LMF2M, Annaba, Algeria \\ ${ }^{c}$ University Badji Mokhtar Bp 12-2300, Laboratory of Industrial Mechanics, Annaba, Algeria
}

\begin{abstract}
The principal function of a continuous casting mold is to receive the liquid steel and ensure its cooling in order to permit the formation of a solidified and sufficiently resistant skin. This is the phase of primary cooling. The efficiency of this process depends on several parameters, such as the casting speed, the temperature exchange between the walls of the mold and the thin crust of the slab, as well as the conicity of continuous casting mold. The latter has been the subject of this work, which consists in investigation of the influence of the conicity of mold on the variation of the temperature field, and friction, generated during lowering of the slab. The numerical simulation was carried out using Fluent 6.0 code. The obtained curves reflect changes of the factors mentioned above as a functions of the conicity.
\end{abstract}

DOI: 10.12693/APhysPolA.131.359

PACS/topics: $44.20 .+$ b

\section{Introduction}

In the steel industry, continuous casting is the process that lies between of the steel production and the lamination [1]. This process occupies an important place in production chain because of its advantages over the traditional technique of ingot casting. These are saving of energy and manpower, better yield and an improved product quality [2]. The solidification phase of the ingot is very important. It is influenced by many factors, such as casting speed, casting temperature, lubrication and mold geometry [3]. It is thus clear that an excellent knowledge of this process (Fig. 1) is indispensable if one wants to optimize casting operation, improve product quality and increase the profitability of the process [4].

The liquid steel cast through a submerged nozzle into a mold, will solidify and solid skin will start to form during first phase, called the primary cooling [5]. The mold walls are cooled by water, to extract heat, thereby forming a sufficiently stout skin, to contain the liquid metal and to support the ferrostatic pressure. In course of the descent of slab there is a compression of steel under effect of cooling, resulting in creation of vacuum between the skin and the mold walls. The objective of this work is to observe the effect of mold geometry on temperature field and the coefficient of friction along the wall of the mold, using the Fluent 6.0 numerical code.

\section{Simulation parameters}

\subsection{Material}

Material used in experiments is stainless steel 434. Its main physical properties are indicated in Table I

\footnotetext{
*corresponding author; e-mail: m.bourebia@crti.dz
}

TABLE I

Physical properties of steel [5].

\begin{tabular}{c|c}
\hline \hline Property & Value \\
\hline Thermal conductivity $[\mathrm{W} / \mathrm{m} \mathrm{K}]$ & 26 \\
Density $\rho\left[\mathrm{kg} / \mathrm{m}^{3}\right]$ & 7020 \\
Specific heat $[\mathrm{J} / \mathrm{kg} \mathrm{K}]$ & 680 \\
Liquidus temperature $[\mathrm{K}]$ & 1775 \\
Dynamic viscosity $[\mathrm{kg} / \mathrm{m} \mathrm{s}]$ & 0.0056 \\
Casting temperature $[\mathrm{K}]$ & 1832
\end{tabular}

The speed used in simulations for two molds was $V c=$ $0.1 \mathrm{~m} / \mathrm{s}$.

\subsection{Mold geometry}

In this work, we have considered two geometric forms of continuous casting mold (straight and inclined) Fig. 1.
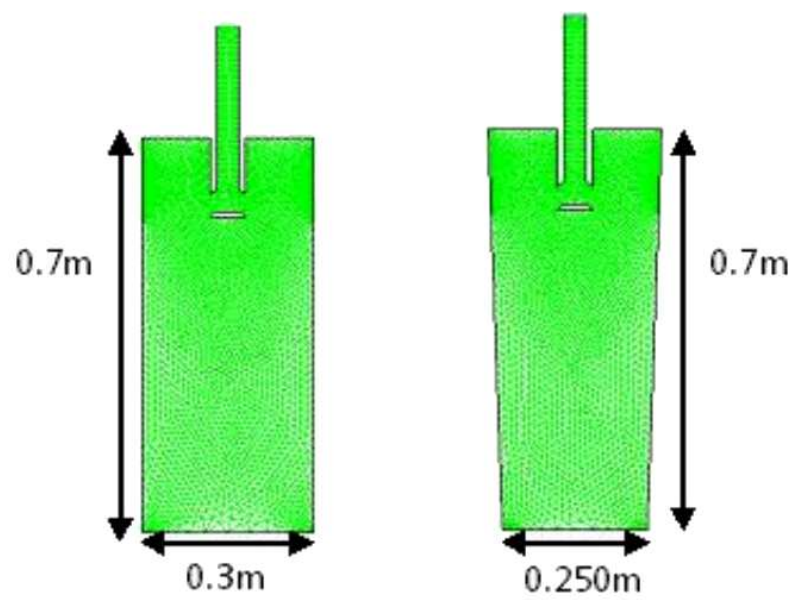

Fig. 1. Mold geometry. 
Dimension of the straight mold (on the left side) were $0.700 \times 0.300 \mathrm{~m}$. Dimensions of the mold, walls of which are inclined at $2^{\circ}$, were $0.700 \times 0.250 \mathrm{~m}$.

\subsection{Mathematical model}

The chosen mathematical model was the turbulence model $k-\varepsilon$ [4].

\subsection{Boundary conditions}

At the mold wall the no-slip condition was imposed for the tangential velocity components and flow, given by

$$
K(T) \frac{\partial T}{\partial x}=-\Phi_{s} .
$$

The flow conditions and stresses are considered zero for free surfaces.

The turbulent kinetic energy and initial dissipation rate of input are estimated using Eq. (2) [6]

$$
K_{\text {in }}=0.01 U_{\text {in }}^{2}, \quad \text { et } \varepsilon_{\text {in }}=K_{\text {in }}^{1.5} / R
$$

Considering thermal conditions, the inlet temperature is imposed to be $T_{\text {inlet }}=1832 \mathrm{~K}\left(1559^{\circ} \mathrm{C}\right)$.

The heat flux removed by mold faces, when moving the meniscus level at the bottom of mold, is expressed as follows [7].

$$
\Phi_{s}\left(\mathrm{~W} / \mathrm{m}^{2}\right)=(1.0-0.7 h) \times 10^{6},
$$

where $h$ is the position of steel wafer corresponding to considered level of meniscus.

\section{Results of simulation and interpretation}

Using two different geometries we can observe the influence of the conicity of mold on certain parameters of primary cooling such as temperature, coefficient of friction.

\subsection{Effect of temperature}

According to the curves of temperatures observed along the walls of the molds (Fig. 2), a significant decrease
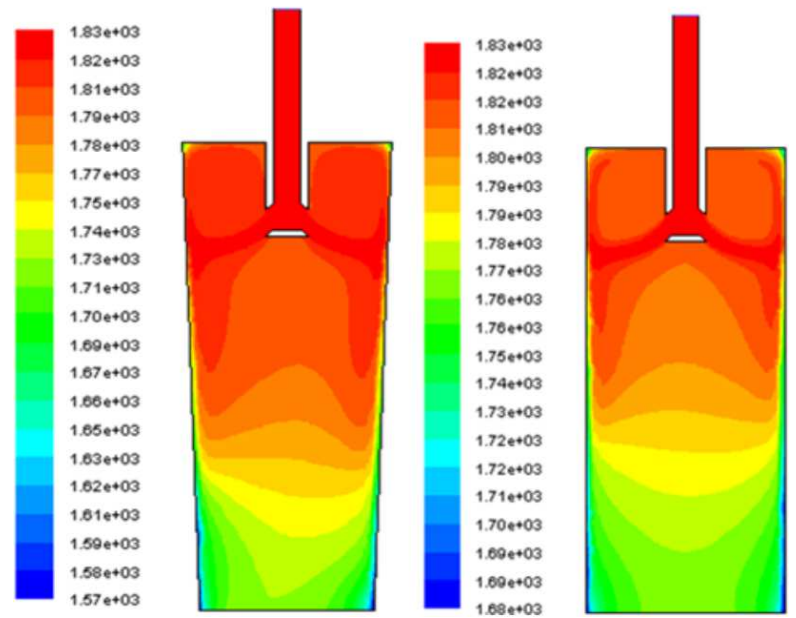

Fig. 2. Variation of temperature along the wall for the two geometries.

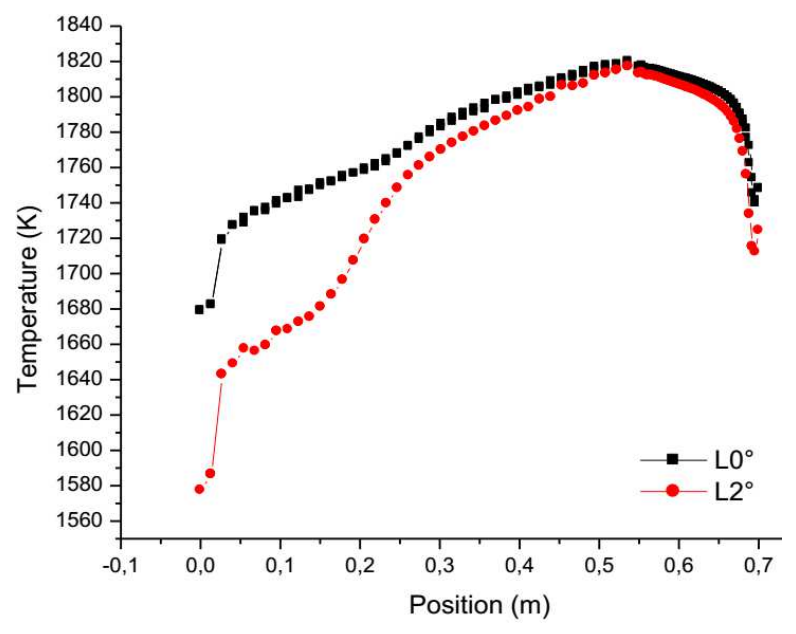

Fig. 3. Comparison between the temperatures of both molds.

in the temperature can be observed at the outlet of the mold with the inclined walls, attaining $1560 \mathrm{~K}$, while for straight mold it is $1680 \mathrm{~K}$ (Fig. 3). In fact, during its movement in the mold the solidified skin of steel is compressed, thus providing the sliding. Then, the inclination of the walls enables solidified skin to keep contact with the cooled walls of the mold. Whereas for the straight mold, when skin formed of steel retracts itself during the descent, the skin loses contact with cooled walls, which explains why the temperature at the output of the mold is higher than that of the inclined mold.

\subsection{Effect of coefficient of friction}

According to the curves in Fig. 4a, friction coefficient is identical for both molds, with the exception of descent between 0.5 and $0.4 \mathrm{~m}$, where there is an increase in the friction coefficient for right mold, compared to inclined walls (Fig. 4b). This phenomenon is explained by fact that when steel is powered by gills of nozzle of straight mold the descent of slab is faster, which creates a higher friction.

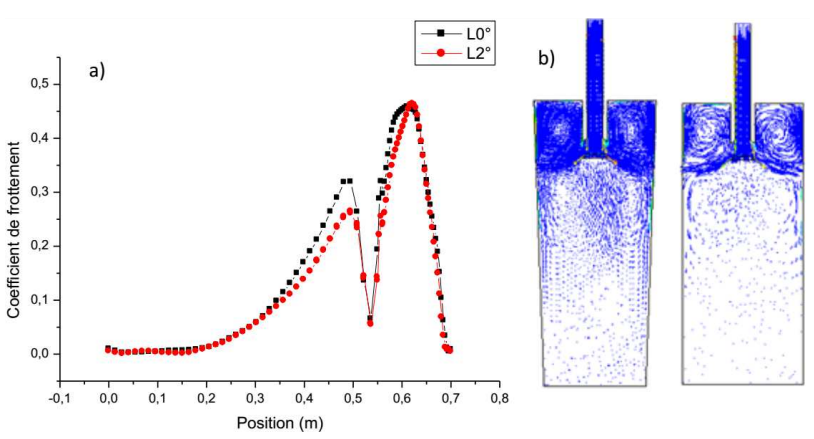

Fig. 4. Coefficient of friction along the wall for two geometries of the mold. 


\subsection{Effect on parameters of $K-\varepsilon$ model}

For illustrating the influence of turbulence model $K-\varepsilon$, Figs. 5, and 6 , respectively, represent the values of kinetic energy $K$ and the dissipation rate for two geometries of mold. It is noted that maximum amplitude of turbulent dissipation rate and kinetic energy is registered at a height of $0.50 \mathrm{~m}$ and $0.55 \mathrm{~m}$ at from the outlets of nozzle, respectively.

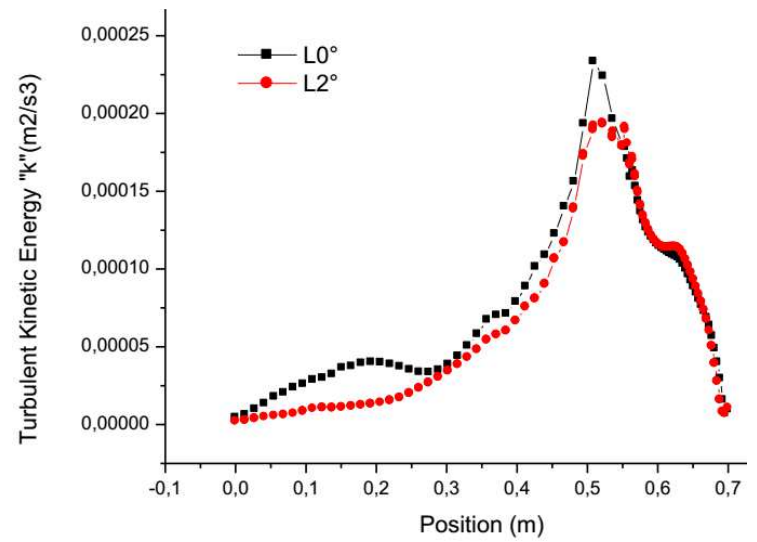

Fig. 5. Kinetic energy $K$ near the wall for two geometries of mold.

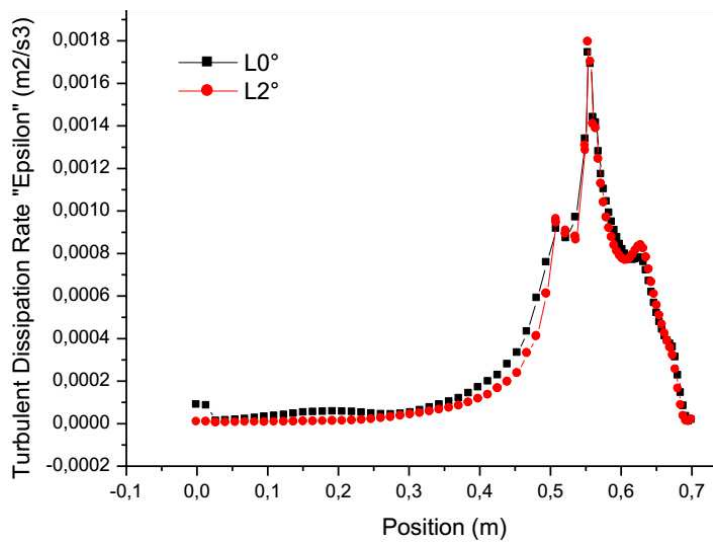

Fig. 6. Dissipation rate near the wall for two geometries of mold.

\section{Conclusions}

The process of continuous casting of steel is governed by several parameters, which interact at the same time and which directly affect the primary cooling process. Among these factors is the geometry of the casting mold. Therefore, the results obtained through this simulation have enabled to highlight the positive influence of the geometry of the mold on the temperature field along the traverse of the solidified skin in the mold. Thus the conicity of the mold enables the retraction of the slab during the solidification of the steel, which is reflected by the lower temperatures at the output of mold, compared to ordinary straight mold. Accordingly, adopted numerical model confirms the formation of the solidified skin. In future we will try to study the optimal degree of taper of a mold.

\section{References}

[1] C. Fréderic, ENSMP Ph.D. Thesis, Higher National School of Mines of Paris, 2004.

[2] M. Bensouici, Ph.D. Thesis, University MentouriConstantine, Faculty of Science Engineering, Mechanical Engineering Department, 2007.

[3] M. Bourebia, H. Maouche, S. Bouhouche, M. Chaour, S. Boulkroune, L. Laouar, in: Industrial Engineering and Operations Management (IEOM), IEEE, 2015.

[4] M. Henri, Ph.D. Thesis, Higher National School of Mines of Paris, 2009.

[5] A. Ahcene, A. Bellaouar, M. Lachi, Numerical Modeling of 2D Temperature Field in the Area of Primary Cooling of Continuous Casting Machine in: Days of National Studies Mechanics, JENM' 2011.

[6] A. Bellaouar, O. Kholai, F. Daoud, in: 13th International Thermal Days, Jith 2007, p. 5.

[7] A. Bellaouar, O. Kholai, P. Valentin, Bull. Polytechnic Inst. Jassy LI, 77 (2005). 